\title{
Epidemiology of Biopsy Proven Glomerular Disorders and Effect of Severe Cyclone on Its Incidence in Central Queensland Region of Australia
}

\author{
Manaf Aljishi', Tony Pham¹, Justin Chan', Matthew McGrail2, Thin Han"1,2, Jennifer Borg1, \\ Dwarakanathan Ranganathan 3,4 , Zaw Thet ${ }^{1,2,4}$
}

\author{
${ }^{1}$ Department of Nephrology, Central Queensland Hospital and Health Service, Queensland, Australia \\ ${ }^{2}$ The University of Queensland, Rural Clinical School, Rockhampton, Queensland, Australia \\ ${ }^{3}$ Department of Nephrology, Royal Brisbane and Women's Hospital, Queensland, Australia \\ ${ }^{4}$ The Griffith University, Queensland, Australia \\ Email: manaf.aljishi@gmail.com
}

How to cite this paper: Aljishi, M., Pham, T., Chan, J., McGrail, M., Han, T., Borg, J., Ranganathan, D. and Thet, Z. (2021) Epidemiology of Biopsy Proven Glomerular Disorders and Effect of Severe Cyclone on Its Incidence in Central Queensland Region of Australia. Open Journal of Nephrology, 11, $477-488$.

https://doi.org/10.4236/ojneph.2021.114040

Received: August 3, 2021

Accepted: November 22, 2021

Published: November 25, 2021

Copyright $\odot 2021$ by author(s) and Scientific Research Publishing Inc. This work is licensed under the Creative Commons Attribution International License (CC BY 4.0).

http://creativecommons.org/licenses/by/4.0/

\begin{abstract}
Aim: The objectives of this study are to determine the epidemiology of biopsy-proven glomerular disease (GD) in Central Queensland and the effect of a severe cyclone on its incidence and clinical phenotype. Background: Central Queensland (CQ) has a relatively high incidence of kidney disease. Since its biopsy service commenced in 2005, there have been no data on biopsy-proven GD. It has been suggested that GD incidence changes around times of natural disasters. In February 2015, the CQ region was affected by a category $5 \mathrm{Cy}$ clone Marcia. This provides an opportunity to explore possible environmental triggers of GD. Methods: This was a single-centre retrospective observational study on biopsy-proven kidney disease in CQ. All kidney biopsies performed between January 2005 and December 2019 were included. Patients with biopsy-proven GD during 3 years before and after Cyclone Marcia (from 2012 to 2018) were analysed. Results: 170 native kidney biopsies occurred during the 15 years. The number of annual biopsies steadily increased from 7 to 16 . The most common biopsy-proven kidney disease was IgA Nephropathy (27\%) followed by diabetic nephropathy (20\%). GD comprised 64\% of biopsies. Unlike other GD, the incidence of ANCA-associated vasculitis (AAV) significantly increased after cyclone (one pre- and eight post-cyclone, $\mathrm{P}$ value $=$ 0.039). The majority of AAV cases occurred in the first year after the cyclone. Conclusion: Kidney biopsies in CQ provide important epidemiological data on biopsy-proven kidney disease. Cyclones have a possible effect on the inci-
\end{abstract}


dence and clinical phenotype of ANCA associated vasculitis.

\section{Keywords}

Anti-Neutrophil Cytoplasmic Antibody-Associated Vasculitis, Australia, Cyclonic Storms, Glomerulonephritis, Kidney Biopsy, Queensland

\section{Introduction}

Chronic kidney disease (CKD) touches the lives of many Australians and approximately 1 in 10 Australian adults has some clinical sign of kidney disease [1]. Over 2000 people start kidney replacement therapy (dialysis or transplant) every year [2]. Glomerular disease (GD) is a major cause of CKD and the second leading cause of end-stage renal failure in Australasia, accounting for 16\% - 18\% of underlying kidney disease [3]. However, unlike general CKD, much less is known about the epidemiology, aetiology and environmental association for GD. Studies on the epidemiology of GD may shed light on its aetiology. Central Queensland (CQ) is one of Australia's CKD hot spots, with an estimated CKD prevalence of $13 \%$ compared to the national average of $10 \%$ [4].

It has been suggested that environmental factors are implicated in the pathogenesis of GD and are associated with changing incidence of GD. Many socially and environmentally determined factors have been linked with the development of GD, such as air pollution in membranous nephropathy [5], heavy metals in minima change disease [6], and smoking and hydrocarbon inhalation in antiglomerular basement membrane disease [7].

There have been no studies to date on the effects of cyclone on kidney disease. There have been several publications looking at the effects of other natural disasters on the rates of AAV (Table 1).

Table 1. Summary of studies that evaluated the effect of major environmental disasters on the incidence of ANCA associated vasculitis.

\begin{tabular}{|c|c|c|c|c|}
\hline Country (Year) (Author) & $\begin{array}{l}\text { Environmental } \\
\text { factors (severity) }\end{array}$ & $\begin{array}{l}\text { Study } \\
\text { outcome }\end{array}$ & Type of ANCA & Pulmonary involvement \\
\hline \multicolumn{5}{|l|}{ Renal Vasculitis studies } \\
\hline $\begin{array}{l}\text { Japan (2011) } \\
\text { (The Great East) } \\
\text { Takeuchi et al. [10] }\end{array}$ & $\begin{array}{c}\text { Earthquake } \\
\text { (magnitude 9.0) }\end{array}$ & Positive & $\mathrm{MPO}>\mathrm{PR} 3$ & $\begin{array}{l}\text { Ground glass changes in CT chest } \\
\qquad(65 \%)\end{array}$ \\
\hline $\begin{array}{l}\text { New Zealand (2011) } \\
\quad(\text { Christchurch) } \\
\text { Farquhar et al. }[11]\end{array}$ & $\begin{array}{c}\text { Earthquake } \\
\text { (magnitude 6.4) }\end{array}$ & Negative & $\mathrm{PR} 3>\mathrm{MPO}$ & $\begin{array}{l}\text { Upper respiratory }(40 \%) \\
\text { Lower respiratory }(48 \%)\end{array}$ \\
\hline $\begin{array}{c}\text { Japan (1995) } \\
\text { (Kobe) } \\
\text { Yashiro et al. [9] }\end{array}$ & $\begin{array}{c}\text { Earthquake } \\
\text { (magnitude } 7.2 \text { ) }\end{array}$ & Positive & $\mathrm{MPO}>\mathrm{PR} 3$ & Pulmonary symptoms (57\%) \\
\hline
\end{tabular}




\section{Continued}

Pulmonary Vasculitis study

Japan (2011)

(Tohoku Region)

Ebisawa et al. [12]
Earthquake

(magnitude $<6$ )
ANCA results:

18.2\% (Pre-), $14.3 \%$

(Post-earthquake)
Significant increase in silica on

bronchoscopy lung lavages but no

difference in lung haemorrhage

The incidence of glomerulonephritis has been posited to be higher following an earthquake in earthquake-affected districts compared to non-affected areas [8]. Rates of ANCA-associated vasculitis (AAV) following earthquakes in Japan showed a significant increase in MPO positive AAV, concluding that environmental agents may have a role in the pathogenesis of AAV [9] [10]. One study was conducted looking at the rates of AAV following the 1995 Kobe earthquake in Japan which demonstrated a significant increase in MPO associated AAV [9]. Another study in Japan showed that the incidence of MPO associated AAV was increased significantly after a severe earthquake [10]. However, these findings were not replicated in all studies: a similar study that examined the rates of AAV three years before and after the earthquake in Christchurch in New Zealand found no difference between both groups [11]. The difference from both studies could be due to different racial demographics, population density, air quality post-earthquake and type of vasculitis and the degree of damage caused by the earthquakes. The magnitude of the earthquake in Japan were 9.0 and 7.2 Richter, respectively, whereas 6.4 Richter in Christchurch, New Zealand [9] [10] [11].

CQ region is prone to natural disasters. In February 2015, the CQ region was heavily affected by a category 5 Cyclone Marcia. Cyclones can have a direct impact on health via their physical damage and indirect effects due to the aftermath of environmental and social changes. Studying the health effects of cyclones has become increasingly important, especially as cyclones have become more common and intense around the globe in recent decades, especially in Australia which sits across two ocean basins where cyclones form the Southern Indian Ocean and the Southern Pacific Ocean [13].

Since kidney biopsy service commenced in CQ in 2005, there have been no epidemiological data on biopsy-proven kidney disease or GD in particular. Although Australia is frequently affected by environmental disasters such as cyclones and severe storms, there have been no studies to date conducted locally to assess if there is any correlation between them and the incidence of GD. Therefore, the objectives of this study are firstly to determine the background epidemiology of biopsy-proven kidney disease in CQ and secondly to assess the effect of a severe cyclone on the incidence and clinical phenotype of GD.

\section{Method}

This was a single centre retrospective observational study conducted in CQ. The data on kidney biopsies, which were performed from when kidney biopsy service started to the end of the study period (January 2005 to December 2019), were collected to determine the background epidemiology of biopsy-proven kidney 
disease.

Inclusion criteria are all CQ patients with biopsy-proven GD from 3 years before Cyclone Marcia ( $1^{\text {st }}$ of February 2012-28 $8^{\text {th }}$ of February 2015) and 3 years after cyclone ( $1^{\text {st }}$ of March $2015-28^{\text {th }}$ of February 2018). Exclusion criteria were GD secondary to other conditions, such as hepatitis B or C virus, HIV-associated nephropathy, plasma cell dyscrasias, and paraneoplastic glomerulopathy. GD patients without biopsies were also excluded.

Data on serology results, organ involvement, requirements of dialysis/plasma exchange, kidney function, pre-existing risk factors including occupation, medications and smoking status pre- and post-cyclone were collected from existing hospital electronic and paper health records. The Charlson Comorbidity Index [14] was calculated by determining the patient's comorbidities from their health records at the time of their biopsy.

The study was approved by Central Queensland Human Research Ethics Committee and the local governance authority (HREC/17/QCQ/7)) in Central Queensland Hospital and Health Service on 02/01/2018.

Continuous variables were reported as means with standard deviations, and medians whereas categorical variables were expressed as number (values) and percentage. Data summary and graphs were performed using Microsoft Excel, and data analysis was performed using Stata/SE v15.1. Quantitative data were compared with the use of Fisher's exact test for counts and Incidence Rate Ratios (IRR) for event rates. The level of significance was set at a two-tailed p-value of $\leq 0.05$.

\section{Results}

187 kidney biopsies occurred during the 15-year study period, of which 170 (91\%) were native biopsies. The number of kidney biopsies performed per year has steadily increased over the years from 7 in 2005 to 16 in 2018. The median age of patients who underwent kidney biopsy was 52 years (SD 16 years), 107 (57\%) of them are males. The most common reasons for ordering native kidney biopsy were acute kidney injury (54\%), nephritic syndrome (34\%), subnephrotic proteinuria (30\%) and nephrotic syndrome (30\%). Among patients presenting with nephrotic syndrome, the most common diagnoses were minimal change disease, (23\%), primary focal segmental glomerulosclerosis (23\%) and membranous nephropathy (20\%).

The most common diagnosis on biopsy was IgA Nephropathy (27\% of biopsies) followed by diabetic nephropathy (20\%) and membranous nephropathy (18\%) (Table 2). GD accounted for $64 \%$ of biopsy findings. Most GDs had stable incidence during the study period, except for a spike in AAV incidence in 2015 (Figure 1).

\section{Cyclone Data}

ANCA-associated vasculitis (AAV) was the only GD that showed a significant increase in incidence after cyclone Marcia (pre-cyclone: 1 case, 1.5 cases per million-person years; post-cyclone: 8 cases, 12.1 cases per million-person years, 
Table 2. List of diagnoses on kidney biopsies in central Queensland.

\begin{tabular}{|c|c|}
\hline Biopsy Diagnosis & Number (percentage) \\
\hline IgA Nephropathy & $27(27 \%)$ \\
\hline Diabetic Nephropathy & $20(20 \%)$ \\
\hline Membranous Nephropathy & $18(18 \%)$ \\
\hline Focal Segmental Glomerulosclerosis & $17(17 \%)$ \\
\hline ANCA Vasculitis & $16(16 \%)$ \\
\hline Minimal Change Disease & $8(8 \%)$ \\
\hline Lupus Nephritis & $8(8 \%)$ \\
\hline Membranoproliferative Glomerulonephritis & $7(7 \%)$ \\
\hline Normal & $7(7 \%)$ \\
\hline Acute Tubular Necrosis & $6(6 \%)$ \\
\hline Interstitial Nephritis & $5(5 \%)$ \\
\hline Thrombotic Microangiopathy & $4(4 \%)$ \\
\hline Amyloidosis & $4(4 \%)$ \\
\hline Acute Interstitial Nephritis & $3(3 \%)$ \\
\hline Insufficient Biopsy & $3(3 \%)$ \\
\hline Glomerulonephritis Unclassified & $3(3 \%)$ \\
\hline Glomerulosclerosis & $3(3 \%)$ \\
\hline Paraprotein-related Nephropathy & $2(2 \%)$ \\
\hline Fibrillary Glomerulonephritis. & $2(2 \%)$ \\
\hline Post-Infectious Glomerulonephritis & $2(2 \%)$ \\
\hline Anti-GBM Disease & $2(2 \%)$ \\
\hline Chronic Kidney Disease Unclassified & $2(2 \%)$ \\
\hline HIV Nephropathy & $1(1 \%)$ \\
\hline
\end{tabular}

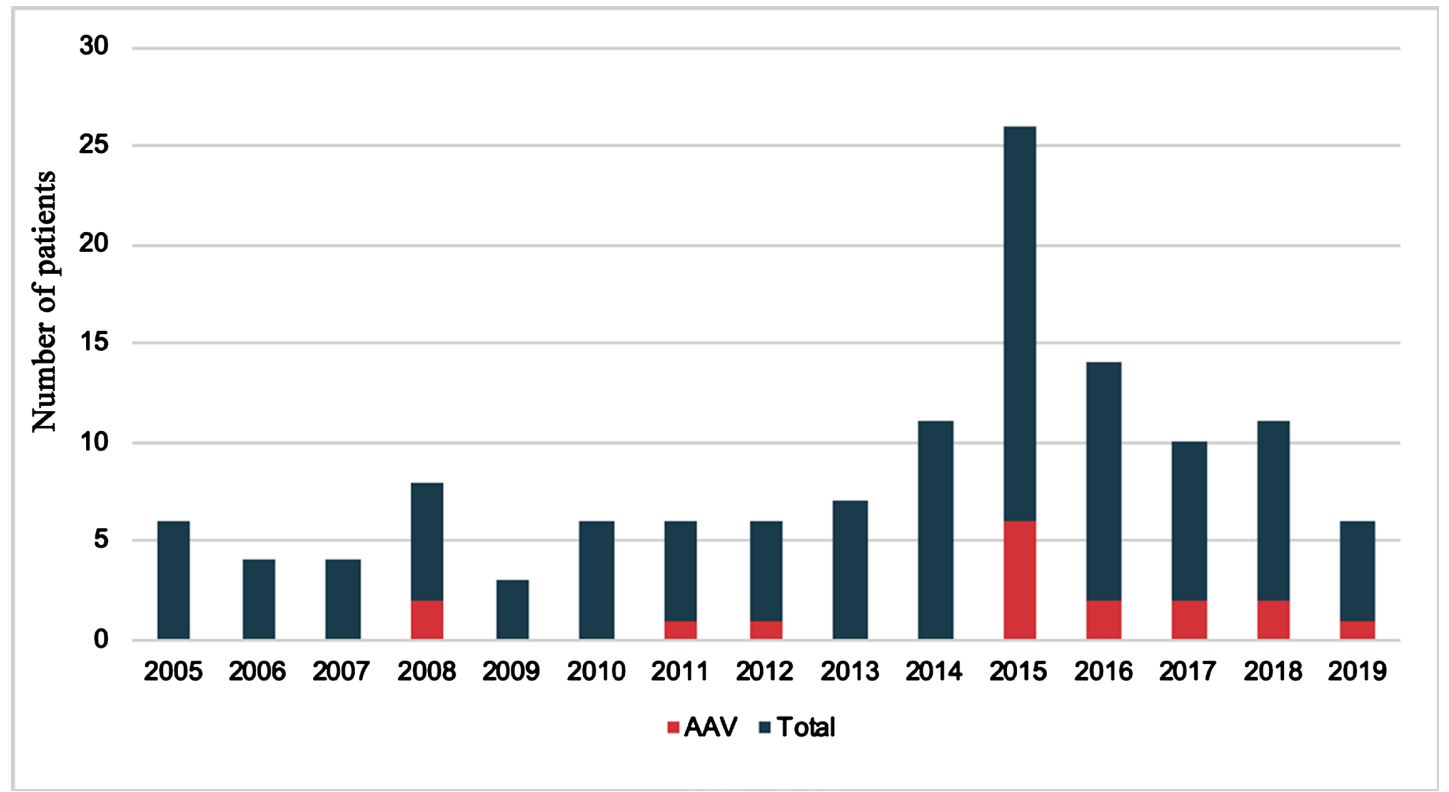

Figure 1. Trend of total kidney biopsies and ANCA-associated vasculitis during the period 2005 to 2019 in Central Queensland. 
with incidence rate ratio (IRR) of $8.0,95 \%$ CI $1.1-354, \mathrm{p}=0.039$ ). IRR was 2.7 $(\mathrm{p}=0.23)$ for IgA Nephropathy, $4(\mathrm{p}=0.38)$ for lupus nephritis, $2.3(\mathrm{p}=0.34)$ for membranous nephropathy, and $1.5(\mathrm{p}=0.05)$ for minimal change disease.

There were more smokers in the post-cyclone GD groups compared to precyclone group, and this is most pronounced in the AAV group ( $88 \%$ vs $0 \%$ ) (Table 3). The relative severity of renal involvement in post-cyclone GD compared to

Table 3. Epidemiology and characteristics of glomerulonephritis cases before and after Cyclone Marcia. P-value was calculated using Fisher's exact test. Incidence was calculated based on Central Queensland population of 220,291 in 2016 [15].

\begin{tabular}{|c|c|c|c|c|c|c|c|c|c|c|c|c|c|c|c|}
\hline & \multicolumn{3}{|c|}{ ANCA Vasculitis } & \multicolumn{3}{|c|}{ IgA Nephropathy } & \multicolumn{3}{|c|}{ Lupus Nephritis } & \multicolumn{3}{|c|}{$\begin{array}{l}\text { Membranous } \\
\text { Nephropathy }\end{array}$} & \multicolumn{3}{|c|}{$\begin{array}{c}\text { Minimal Change } \\
\text { Disease }\end{array}$} \\
\hline & $\begin{array}{l}\text { Pre- } \\
\text { cyclone }\end{array}$ & $\begin{array}{l}\text { Post- } \\
\text { cyclone }\end{array}$ & $\begin{array}{c}P \\
\text { value }\end{array}$ & $\begin{array}{c}\text { Pre- } \\
\text { cyclone }\end{array}$ & $\begin{array}{l}\text { Post- } \\
\text { cyclone }\end{array}$ & $\begin{array}{c}P \\
\text { value }\end{array}$ & $\begin{array}{l}\text { Pre- } \\
\text { cyclone }\end{array}$ & $\begin{array}{l}\text { Post- } \\
\text { cyclone }\end{array}$ & $\begin{array}{c}P \\
\text { value }\end{array}$ & $\begin{array}{c}\text { Pre- } \\
\text { cyclone }\end{array}$ & $\begin{array}{l}\text { Post- } \\
\text { cyclone }\end{array}$ & $\begin{array}{c}P \\
\text { value }\end{array}$ & $\begin{array}{c}\text { Pre- } \\
\text { cyclone }\end{array}$ & $\begin{array}{l}\text { Post- } \\
\text { cyclone }\end{array}$ & $\begin{array}{c}\mathbf{P} \\
\text { value }\end{array}$ \\
\hline Number & & & 0.039 & & & 0.23 & & & 0.38 & & & 0.34 & & & 1 \\
\hline $\begin{array}{l}\text { (Incidence rate per } \\
\text { million }\end{array}$ & $\begin{array}{l}\mathrm{N}=1 \\
(1.51)\end{array}$ & $\begin{array}{l}\mathrm{N}=8 \\
(12.07)\end{array}$ & $\begin{array}{c}(0.00 \\
-\end{array}$ & $\begin{array}{l}\mathrm{N}=3 \\
(4.53)\end{array}$ & $\begin{array}{l}\mathrm{N}=8 \\
(12.07)\end{array}$ & $\begin{array}{c}(0.06 \\
-\end{array}$ & $\begin{array}{l}\mathrm{N}=1 \\
(1.51)\end{array}$ & $\begin{array}{l}\mathrm{N}=4 \\
(6.04)\end{array}$ & $\begin{array}{c}(0.01 \\
-\end{array}$ & $\begin{array}{l}\mathrm{N}=3 \\
(4.53)\end{array}$ & $\begin{array}{l}\mathrm{N}=7 \\
(10.56)\end{array}$ & $\begin{array}{c}(0.07 \\
-\end{array}$ & $\begin{array}{l}\mathrm{N}=2 \\
(3.02)\end{array}$ & $\begin{array}{l}\mathrm{N}=3 \\
(4.53)\end{array}$ & $\begin{array}{c}(0.06 \\
-\end{array}$ \\
\hline person-years) & & & $0.93)$ & & & $1.56)$ & & & $2.53)$ & & & $1.88)$ & & & $5.82)$ \\
\hline Male/Female & $0 / 1$ & $5 / 3$ & & $2 / 1$ & $5 / 3$ & & $0 / 1$ & $2 / 2$ & & $3 / 0$ & $6 / 1$ & & $2 / 0$ & $2 / 1$ & \\
\hline Age (mean) & 69 & 60.1 & & 50 & 42.6 & & 54 & 34.8 & & 38.0 & 51.0 & & 22 & 50.3 & \\
\hline \multicolumn{16}{|l|}{ Season of diagnosis } \\
\hline Summer & 1 & 1 & & 0 & 0 & & 0 & 2 & & 0 & 2 & & 0 & 1 & \\
\hline Autumn & 0 & 3 & & 0 & 2 & & 1 & 1 & & 2 & 1 & & 1 & 1 & \\
\hline Winter & 0 & 2 & & 1 & 2 & & 0 & 0 & & 1 & 2 & & 0 & 0 & \\
\hline Spring & 0 & 2 & & 2 & 4 & & 0 & 1 & & 0 & 2 & & 1 & 1 & \\
\hline $\begin{array}{l}\text { Mean BMI } \\
\left(\mathrm{kg} / \mathrm{cm}^{2}\right)\end{array}$ & 22.4 & 25.7 & & 24.1 & 35.2 & & 32.3 & 33.2 & & 30.2 & 27.8 & & 26.3 & 31.5 & \\
\hline Aboriginal or & & & & & & & & & & & & & & & \\
\hline $\begin{array}{l}\text { Torres Strait } \\
\text { Islander }\end{array}$ & 0 & 0 & & 0 & 1 & & 0 & 1 & & 1 & 1 & & 0 & 0 & \\
\hline Ever smoked & 0 & 7 & & 3 & 4 & & 0 & 1 & & 2 & 6 & & 1 & 2 & \\
\hline $\begin{array}{l}\text { Creatinine (mean } \\
\text { peak value) } \\
\text { (umol/L) }\end{array}$ & 108 & 448 & & 178 & 157 & & 118 & 100 & & 110 & 110 & & 234 & 151 & \\
\hline $\begin{array}{c}\text { eGFR } \\
\left(\mathrm{ml} / \mathrm{min} / 1.73 \mathrm{~m}^{2}\right)\end{array}$ & 43 & 17 & & 42 & 52 & & 45 & 74 & & 70 & 73 & & 54 & 54 & \\
\hline $\begin{array}{l}\text { Urine PCR } \\
(\mathrm{mg} / \mathrm{mol})\end{array}$ & 261 & 207 & & 672 & 730 & & 792 & 211 & & 230 & 805 & & 540 & 1041 & \\
\hline WCC $\left(\times 10^{9} / \mathrm{L}\right)$ & 8.2 & 8.1 & & 11.8 & 9.4 & & 6.3 & 8.3 & & 8.0 & 8.2 & & 6.7 & 8.0 & \\
\hline $\begin{array}{l}\text { Immunosuppression } \\
\text { treatment }\end{array}$ & 1 & 8 & & 1 & 5 & & 1 & 3 & & 3 & 7 & & 2 & 3 & \\
\hline $\begin{array}{c}\text { Dialysis } \\
\text { Dependence }\end{array}$ & 0 & 3 & & 1 & 1 & & 0 & 0 & & 0 & 0 & & 0 & 0 & \\
\hline Mortality & 0 & 0 & & 0 & 0 & & 0 & 0 & & 0 & 1 & & 0 & 0 & \\
\hline $\begin{array}{c}\text { Charlson } \\
\text { Comorbidity Index }\end{array}$ & 1.0 & 2.1 & & 0.7 & 0.9 & & 2 & 1 & & 0 & 0.6 & & 1 & 1.3 & \\
\hline
\end{tabular}


pre-cyclone was most marked in the AVV group, who had the highest incidence of progression to end-stage kidney failure, despite all post-cyclone AAV cases receiving immunosuppressive therapy.

As AAV occurred more significantly after the cyclone, more analysis on the post-cyclone AAV group was conducted of the 8 cases (Table 4 ). The median age of AAV was 60 years with Caucasian (91\%) and male predominance (63\%). MPO vasculitis was more common than PR3 vasculitis (4 vs. 1 case). Four patients had occupations involving mining. Two cases had extra-renal manifestations. Most AAV cases incidence occurred within the first year after the cyclone, following which the incidence dropped close to pre-cyclone level. There was one case that occurred in the study period before the cyclone, and after three years of

Table 4. Demographic and clinical characteristics of the 8 ANCA associated vasculitis cases after the cyclone in Central Queensland Region.

\begin{tabular}{|c|c|}
\hline Characteristic & Number \\
\hline Median Age (Range) & 60.1 years $(40-73)$ \\
\hline Sex & 6 males, 2 females \\
\hline Ethnicity & $\begin{array}{c}7 \text { Caucasians } \\
1 \text { Middle Eastern }\end{array}$ \\
\hline \multicolumn{2}{|l|}{ Time following the cyclone } \\
\hline First year & 7 \\
\hline Second year & 1 \\
\hline Third year & 0 \\
\hline Creatinine (mean peak) (umol/L) & 448 \\
\hline \multicolumn{2}{|l|}{ Subtype } \\
\hline pANCA/MPO & 4 \\
\hline cANCA/PR3 & 1 \\
\hline Atypical ANCA & 3 \\
\hline \multicolumn{2}{|l|}{ Organ involvement } \\
\hline Renal alone & 6 \\
\hline Renal and sinus/respiratory & 2 \\
\hline \multicolumn{2}{|l|}{ Occupation history } \\
\hline Mining & 4 \\
\hline Farming & 1 \\
\hline Others & 3 \\
\hline \multicolumn{2}{|l|}{ Smoking } \\
\hline Ex-Smoker & 4 \\
\hline Active Smoker & 1 \\
\hline Non-Smoker & 6 \\
\hline
\end{tabular}


remission, it relapsed three months after the cyclone. It was counted only once as a pre-cyclone case.

\section{Discussion}

After this study provided important epidemiological data on biopsy-proven $\mathrm{CKD}$ and GD in the CQ region. It showed that biopsy practice in the region has steadily increased over the years. GD comprised the dominant diagnosis on biopsies, as kidney biopsy is often the gold standard test to confirm these conditions. IgA Nephropathy was the most common biopsy-proven GD, and this is consistent with the literature showing that it represents the most frequent form of primary GD in Queensland and worldwide [16]. Its prevalence is likely even higher than estimated because many patients with isolated haematuria are not biopsied.

This study is the first to describe the relationship between severe cyclone and GD incidence. Prior to the cyclone, AAV was uncommon in the CQ region. From 2007 to 2015 (pre-cyclone 8-year period), there were only 3 cases (1.6 cases per million person-years). This was followed by an increase in incidence after the cyclone (12.1 cases per million person-years). A similar change was not observed in other GDs. This spike in AAV occurred predominantly within the first year following the cyclone, lending further support to its potential link to the cyclone event. Our findings suggested that post-cyclone AAV was relatively more severe with worse kidney function and leading to end-stage kidney failure and dialysis dependence. Therefore, this had a significant long-term impact on patient health and the healthcare system.

Our study attempted to shed light on the pathogenesis of GD by demonstrating a possible link between a severe cyclone and increasing incidence of AAV immediately following the cyclone. Possible triggers include air-borne materials or heavy metals, unearthed dwellings, water-borne pathogens or infectious agents. Although the aetiologies of most GDs remain undefined, many are believed to be initiated by environmental insults, including infectious processes that trigger host responses in genetically susceptible individuals which lead to glomerulonephritis. This progression from host response to autoimmunity could be explained by direct effects on podocytes and other glomerular components or indirect immune mechanisms, such as immune dysregulation, epitope spreading, molecular mimicry and epitope conformational changes [17].

Other cyclone-related environmental changes include possible massive movement of dust and airborne heavy metals, some of which have been identified as potential risk factors for CKD [18]. It is notable that CQ is characterised by a large mining industry that can harbour these particles. One particular material that has received concern is silica, which is linked to mining, construction and stone cutting and refining. CQ is an area with a big mining industry that has had big concerns and government warnings about workplace exposure to silica [19], and a number of our subjects worked in the mining industry. Silica inhalation 
has been associated with AAV [20] [21]. A study following the 2011 Tohoku earthquake in Japan reported higher rates of diffuse alveolar haemorrhages and ANCA positivity, with a significant increase in silica on bronchoscopy lung lavages, suggesting a role of silica in the pathogenesis of the disease [12]. The risk of AAV following silica exposure seems to be increased even after adjusting for other risk factors such as medications, infections and smoking [20] [21] [22] [23]. However, the studies were unable to conclusively link the timing and degree of exposure to silica to the development of AAV. Silica exposure assessments were questionnaire-based, so any histopathological quantification between actual exposure and disease association was not possible. Furthermore, there is a considerable variation in the latency period between exposure and development of the disease from up to a few months in acute exposure to decades with chronic exposure [22]. Therefore, the involvement of silica in AAV aetiology remains speculative for now, with some of the examples above producing conflicting and inconclusive insights.

Another aspect of the cyclone that our study did not examine is the public health consequences which can lead to GDs. Incidence of gglomerular and infective conditions have been found to increase following a natural disaster [8]. It is postulated that wet conditions, health infrastructure and population changes that occur as a result of a cyclone may contribute to crowding, mass displacement, hygiene problems and increased environmental exposure due to damage to dwellings [24].

Our findings of possible link between cyclone and AAV, along with the multiple studies [8] [9] [10] that showed relationship between earthquake and AAV, add further evidence that there is a relationship between environmental factors and the incidence of AAV in severe natural disasters. It is notable that the majority of AAV patients in Japan's earthquakes had AAV related pulmonary involvement whereas only two out of eight patients in our cohort experienced lung complication. MPO-AAV was more common than PR3-AAV in this study which differed from the usual AAV distribution favouring PR3 in Caucasians. The type of ANCA in severe disaster-related AAV patients in Japan was also predominantly MPO-ANCA. Among individuals who have environmental exposure in mining and construction occupations, an increased frequency of MPO-ANCA has been reported [25], and this study is consistent with it, suggesting a possible environmental trigger for ANCA antibody development.

The study has several strengths. It attempted to fill in a gap in a topic that is sparsely studied. All the patient's diagnoses were biopsy-proven rather than presumptive. All ANCA testing was performed in laboratories with the same accreditation using combined immunofluorescence and enzyme-linked immunosorbent assay testing resulting in comparable biochemical results. Future efforts to reduce GD incidence should focus on understanding potential risk factors and mechanisms of GDs, thereby preventing its development and improving detection by increasing awareness and possibly screening populations at risk. We hope the study will enhance efforts to better understand and prevent GDs. 
Initiatives, such as GD registries and collaborative organizations help advance research in this field and coordinate such efforts

The study has several limitations. It is a single centre study with a small population size and incidence counts. Furthermore, we did not have a method to quantify silica exposure (e.g. bronchoscopy lavages) besides relying on patient history and proximity to mining areas and the cyclone. Having said that, it is often difficult to quantify environmental exposures. Epidemiological data shows a considerable variation in the latency period after natural disasters, and so the long-term impact of cyclone exposure, if any, cannot be assessed. The observations were only suggestive of a link with cyclone and did not meet strict criteria for causality.

\section{Conclusion}

In conclusion, this study provided important epidemiological data on biopsy-proven kidney disease in CQ and suggested a possible effect of severe cyclone on the incidence and clinical phenotype of ANCA associated vasculitis. Studies with larger population and disease incidence and longer duration to examine cyclonerelated environmental effects on kidney health will help further evaluate this theory and provide guidance for kidney health services to monitor for and prevent kidney diseases following natural disasters.

\section{Acknowledgements}

We acknowledge Central Queensland Hospital and Health Service for their support. We also acknowledge Pathology Queensland for providing kidney biopsy data. We thank Queensland Renal Biopsy Registry board for collaborating in obtaining ethics approval and using this data to help improve patient outcomes. We thank Central Queensland Hospital and Health Services Medical Research Unit for their Research Seeding Grant to assist in the publication.

\section{Conflicts of Interest}

The authors declare no conflicts of interest regarding the publication of this paper.

\section{References}

[1] Australian Institute of Health and Welfare (2017) Chronic Kidney Disease Compendium.

[2] ANZDATA Registry (2017) The 40th Annual ANZDATA Report. Australia and New Zealand Dialysis and Transplant Registry. Adelaide. http://www.anzdata.org.au

[3] ANZDATA Registry (2019) 42nd Report, Chapter 1: Incidence of Renal Replacement Therapy for End Stage Kidney Disease. Australia and New Zealand Dialysis and Transplant Registry. Adelaide. http://www.anzdata.org.au

[4] Kidney Health Australia (2016) State of the Nation: 2016 Kidney Health WeekChronic Kidney Disease Hot Spots. KHA, Melbourne. 
https://kidney.org.au/uploads/resources/state-of-the-nation-kidney-health-week-20 16-chronic-kidney-disease-hot-spots.pdf

[5] Xu, X., Wang, G., Chen, N., et al. (2016) Long-Term Exposure to Air Pollution and Increased Risk of Membranous Nephropathy in China. Journal of the American Society of Nephrology, 27, 3739-3746. https://doi.org/10.1681/ASN.2016010093

[6] Qin, A.-B., Su, T., Wang, S.-X., et al. (2019) Mercury-Associated Glomerulonephritis: A Retrospective Study of 35 Cases in a Single Chinese Center. BMC Nephrology, 20, 228. https://doi.org/10.1186/s12882-019-1413-Z

[7] Bombassei, G.J. and Kaplan, A.A. (1992) The Association between Hydrocarbon Exposure and Anti-Glomerular Basement Membrane Antibody-Mediated Disease (Goodpasture's Syndrome). American Journal of Industrial Medicine, 21, 141-153. https://doi.org/10.1002/ajim.4700210204

[8] Giri, B.R., Chapagain, R.H., Sharma, S., et al. (2018) Effect of the 2015 Earthquake on Pediatric Inpatient Pattern at a Tertiary Care Hospital in Nepal. BMC Pediatrics, 18, 28. https://doi.org/10.1186/s12887-018-1008-Z

[9] Yashiro, M., Muso, E., Itoh-Ihara, T., et al. (2000) Significantly High Regional Morbidity of MPO-ANCA-Related Angitis and/or Nephritis with Respiratory Tract Involvement after the 1995 Great Earthquake in Kobe (Japan). The American Journal of Kidney Diseases, 35, 889-895. https://doi.org/10.1016/S0272-6386(00)70260-5

[10] Takeuchi, Y., Saito, A., Ojima, Y., et al. (2017) The Influence of the Great East Japan Earthquake on Microscopic Polyangiitis: A Retrospective Observational Study. PLoS $O N E, 12$, e0177482. https://doi.org/10.1371/journal.pone.0177482

[11] Farquhar, H.J., McGettigan, B., Chapman, P.T., et al. (2017) Incidence of Anti-Neutrophil Cytoplasmic Antibody-Associated Vasculitis before and after the February 2011 Christchurch Earthquake. Internal Medicine Journal, 47, 57-61. https://doi.org/10.1111/imj.13246

[12] Ebisawa, K., Yamada, N., Kobayashi, M., et al. (2013) Cluster of Diffuse Alveolar Hemorrhage Cases after the 2011 Tohoku Region Pacific Coast Earthquake. Respiratory Investigation, 51, 2-8. https://doi.org/10.1016/j.resinv.2012.10.002

[13] Kossin, J.P., Knapp, K.R., Olander, T.L. and Velden, C.S. (2020) Global Increase in Major Tropical Cyclone Exceedance Probability over the Past Four Decades. Proceedings of the National Academy of Sciences, 117, 11975-11980. https://doi.org/10.1073/pnas.1920849117

[14] Charlson, M.E., Pompei, P., Ales, K.L. and MacKenzie, C.R. (1987) A New Method of Classifying Prognostic Comorbidity in Longitudinal Studies: Development and Validation. Journal of Chronic Diseases, 40, 373-383. https://doi.org/10.1016/0021-9681(87)90171-8

[15] Australian Bureau of Statistics. 2016 Census QuickStats. https://quickstats.censusdata.abs.gov.au/census services/getproduct/census/2016/q uickstat/036

[16] McGrogan, A., Franssen, C.F.M. and de Vries, C.S. (2011) The Incidence of Primary Glomerulonephritis Worldwide: A Systematic Review of the Literature. Oxford University Press, Oxford.

[17] Couser, W.G. and Johnson, R.J. (2014) The Etiology of Glomerulonephritis: Roles of Infection and Autoimmunity. Kidney International, 86, 905-914. https://doi.org/10.1038/ki.2014.49

[18] Lee, J., Oh, S., Kang, H., et al. (2020) Environment-Wide Association Study of CKD. Clinical Journal of the American Society of Nephrology, 15, 766-775. https://doi.org/10.2215/CJN.06780619 
[19] Workplace Health and Safety Queensland. Reduction in Workplace Exposure Standard for Respirable Crystalline Silica: Queensland Government.

https://www.worksafe.qld.gov.au/safety-and-prevention/hazards/hazardous-exposu res/respirable-crystalline-silica/respirable-crystalline-silica-general/reduction-in-wo rkplace-exposure-standard-for-respirable-crystalline-silica

[20] Beaudreuil, S., Lasfargues, G., Lauériere, L., et al. (2005) Occupational Exposure in ANCA-Positive Patients: A Case-Control Study. Kidney International, 67, 1961-1966.

https://doi.org/10.1111/j.1523-1755.2005.00295.x

[21] Hogan, S.L., Cooper, G.S., Savitz, D.A., et al. (2007) Association of Silica Exposure with Anti-Neutrophil Cytoplasmic Autoantibody Small-Vessel Vasculitis: A Population-Based, Case-Control Study. Clinical Journal of the American Society of Nephrology, 2, 290-299. https://doi.org/10.2215/CJN.03501006

[22] Gómez-Puerta, J.A., Gedmintas, L. and Costenbader, K.H. (2013) The Association between Silica Exposure and Development of ANCA-Associated Vasculitis: Systematic Review and Meta-Analysis. Autoimmunity Reviews, 12, 1129-1135.

https://doi.org/10.1016/j.autrev.2013.06.016

[23] Stamp, L.K., Chapman, P.T., Francis, J., et al. (2015) Association between Environmental Exposures and Granulomatosis with Polyangiitis in Canterbury, New Zealand. Arthritis Research \& Therapy, 17, 333. https://doi.org/10.1186/s13075-015-0852-6

[24] United Nations Development Programme (2004) Bureau for Crisis P. Reducing Disaster Risk: A Challenge for Development-A Global Report. United Nations, New York.

[25] Wichmann, I., Sanchez-Roman, J., Morales, J., et al. (1996) Antimyeloperoxidase Antibodies in Individuals with Occupational Exposure to Silica. Annals of the Rheumatic Diseases, 55, 205-207. https://doi.org/10.1136/ard.55.3.205 